\title{
Editorial: Call for Papers Focused Collection of Physical Review Physics Education Research Instructional labs: Improving traditions and new directions
}

\author{
Guest Editors \\ Eugenia Etkina, ${ }^{1}$ Gorazd Planinsic, ${ }^{2}$ and Benjamin $Z w i c k l^{3}$
}

Physics is an experimental science. Instructional laboratories where students conduct experiments, analyze data, arrive at conclusions, and communicate findings have been around for over a century. Every physics department has labs of different levels: from introductory to advanced, for majors and nonmajors, with real equipment or virtual.

Throughout the 1980s and 1990s the PER community made significant progress in innovative instructional strategies and research studies related to student learning in lecture and recitation format classes as well as innovative laboratory techniques (for example, microcomputer-based laboratories). Over the last 15 years, we have seen rapid growth in research related to laboratory education. Studies have addressed topics such as the effectiveness of traditional labs, innovative labs where students design their own experiments, student understanding of experimental uncertainties, virtual and remote labs, the modeling process and troubleshooting, and student attitudes towards experimental work. With the development of new instructional strategies and new technologies came new theoretical frameworks and new assessment instruments. As new research tools and techniques emerge, we learn more about student reasoning and growth.

The goal of this Focused Collection is to assemble a set of research articles that together will provide readers with a critical examination of the breadth of pedagogical approaches, frameworks and research methods, assessment tools, and broader issues surrounding laboratory education. This collection envisions articles covering (but not limited to) the following:

- Goals and purposes of laboratory instruction

- Theoretical frameworks and methods for studying labs

- Labs at all levels (K-12, introductory, upper-division/advanced, graduate level)

- Varying student populations (e.g., labs for majors and nonmajors)

- Diversity and inclusion in laboratory education

- Social aspects of lab instruction (group work, roles)

- Different environments and formats of labs (integrated labs, stand-alone labs)

- Virtual and remote labs

- Labs that are placed outside schools/universities (industry, research institutes)

- Assessment and research tools

- Integrating laboratory instruction with theory and/or computation

- Role of educational technology in teaching labs

We invite papers on any of the above topics that clearly show how their work enriches physics education. We encourage submissions from physics education researchers, other disciplinebased education research fields, and from non-PER researchers (learning sciences experts, physicists, etc.). Submissions from all types of institutions and all countries are encouraged.

Submission Guidelines. - Interested authors should submit 500-word proposals for full papers by February 1, 2022, to the guest editors, Eugenia Etkina, Gorazd Planinsic, and Benjamin Zwickl at labs.prper@gmail.com. Proposals for manuscripts of empirical studies, review manuscripts, and theoretical manuscripts are welcome; each proposal must clearly indicate the type of manuscript that is envisioned. Submission requirements are as follows:

\footnotetext{
${ }^{1}$ https://orcid.org/0000-0002-5068-7803

${ }^{2}$ https://orcid.org/0000-0002-5618-7770

${ }^{3}$ https://orcid.org/0000-0002-8925-6912
} 
- Proposals for manuscripts of empirical studies must describe the theoretical basis of the work, the research question(s), and research methods that will be used, including data analysis.

- Proposals for review and theoretical manuscripts should include the motivation for the review topic and a sampling of references that will be used in the article.

All proposals must include contact information and institutional affiliation of the lead author.

The guest editors will, in consultation with the PRPER editor, Charles Henderson, review proposals and notify authors of the status of their submission by May 1, 2022. Authors of accepted proposals will be asked to prepare manuscripts that will go through the standard PRPER review process. Complete manuscripts will be due by May 1, 2023. We expect the submitted manuscripts to be complete works. Works in progress or incomplete articles will be returned to the author without review. This Focused Collection is expected to be published in Spring of 2024.

This focused collection will be supported by a prospective advisory board comprised of

- Duane Deardorff (UNC Chapel Hill)

- Raimund Girwidz (Ludwig Maximilians University, Munich)

- Natasha Holmes (Cornell University)

- Fred Lubben (University of York, UK)

- Laura Rios (California Polytechnic State University)

- MacKenzie Stetzer (University of Maine)

- Muhammad Sabieh Anwar (LUMS University, Pakistan)

Volunteers to review articles are welcome; please send a message to the guest editors at labs .prper@gmail.com.

PRPER is an open-access journal with articles published by the American Physical Society under the terms of the Creative Commons Attribution 4.0 International license. Please note that all normal PRPER policies, including article processing charges, apply. See https://journals.aps .org/prper/about for more information about the journal.

Published 17 November 2021

Charles Henderson

Editor

DOI: 10.1103/PhysRevPhysEducRes.17.020002 